\title{
A STUDY OF INFLUENCE OF DEXMEDETOMIDINE PREMEDICATION ON CHANGES IN INTRAOCULAR PRESSURE FOLLOWING ADMINISTRATION OF SUCCINYLCHOLINE AND ENDOTRACHEAL INTUBATION
}

\author{
Payaswinee1, Deepesh Gupta², S. N. Agarwal ${ }^{3}$
}

${ }_{1}^{1}$ Resident, Department of Anaesthesiology, Gandhi Medical College, Bhopal, Madhya Pradesh.

${ }^{2}$ Associate Professor, Department of Anaesthesiology, Gandhi Medical College, Bhopal, Madhya Pradesh.

3Professor, Department of Anaesthesiology, Gandhi Medical College, Bhopal, Madhya Pradesh.

\begin{tabular}{l}
\hline ABSTRACT \\
\hline BACKGROUND \\
Emergency surgeries for penetrating eye trauma may be complicated by elevation in intraocular pressure (IOP) caused by \\
succinylcholine administration and endotracheal intubation. Hence, it is critical to attenuate the rise in IOP for better outcome. This \\
study was conducted to evaluate the effect of dexmedetomidine premedication in attenuating the rise in IOP due to succinylcholine \\
and endotracheal intubation.
\end{tabular}

\section{MATERIALS AND METHODS}

This non-randomised controlled trial was conducted on 70 American Society of Anesthesiologists (ASA) grade I-II patients, aged 18-60 years undergoing non-ophthalmic surgeries under general anaesthesia (GA). The patients were divided into two groups of 35 each. Group 'C' (control) received $10 \mathrm{~mL}$ normal saline, while Group 'D' (study group) received dexmedetomidine $(0.5 \mu \mathrm{g} / \mathrm{kg}$ ) with normal saline added to make a total volume of $10 \mathrm{~mL}$. IOP, heart rate (HR), systolic blood pressure (SBP), diastolic blood pressure (DBP) and mean arterial pressure (MAP) were recorded before and after premedication, after induction of anaesthesia, after succinylcholine administration immediately and 5 minutes post-intubation.

\section{RESULTS}

Data were compared using independent student ' $t$ ' test and chi-square test in Statistical Package for Social Sciences (SPSS) software version 22. P-value $<0.05$ was considered significant. The rise in IOP, mean HR and MAP were significantly reduced after premedication in Group 'D.' The incidence of side effects between the groups was not significantly different.

\section{CONCLUSION}

The study led to the conclusion that dexmedetomidine premedication significantly attenuates the rise in IOP in response to succinylcholine administration and endotracheal intubation without any additional side-effects and can be used in emergency ophthalmic surgeries for this purpose.

\section{KEYWORDS}

Succinylcholine, Premedication, Intraocular Pressure.

HOW TO CITE THIS ARTICLE: Payaswinee, Gupta D, Agarwal SN. A study of influence of dexmedetomidine premedication on changes in intraocular pressure following administration of succinylcholine and endotracheal intubation. J. Evolution Med. Dent. Sci. 2018;7(07):824-828, DOI: 10.14260/jemds/2018/188

\section{BACKGROUND}

Emergency surgeries for management of penetrating eye injuries present a challenge for anaesthesiologists. As these patients have or are presumed to have full stomach they are at a higher risk of aspiration, which makes rapid sequence intubation the preferable modality. Moreover, succinylcholine, the most commonly used muscle relaxant for rapid sequence intubation causes a significant rise in intraocular pressure (IOP),[1] which may lead to the drainage of aqueous fluid or extrusion of vitreous through the wound, the latter of which can permanently worsen the vision.

'Financial or Other Competing Interest': None.

Submission 15-11-2017, Peer Review 30-01-2018,

Acceptance 05-02-2018, Published 12-02-2018.

Corresponding Author:

Dr. Deepesh Gupta,

\#20, Globus Greens,

Airport Road,

Near Lalaghati, Bhopal,

Madhya Pradesh.

E-mail: deepeshg25@gmail.com

DOI: $10.14260 /$ jemds $/ 2018 / 188$

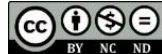

Various techniques like self-taming and adjuvants like lidocaine, sufentanil, gabapentin,[2,3] etc. have been investigated for attenuating the rise in IOP, but none was proved to be successful without drawbacks.

Dexmedetomidine, a highly selective alpha-2 adrenergic agonist, has sedative and analgesic effects as well as sympatholytic effects. ${ }^{[4]}$ These properties prompted us to evaluate the influence of dexmedetomidine premedication on changes in IOP in response to succinylcholine administration and endotracheal intubation.

\section{MATERIALS AND METHODS}

This non-randomised controlled trial was conducted after obtaining clearance from Institutional Ethics Committee and written informed consent from all the study subjects. The included subjects were 70 patients of both sexes aged between 18 and 60 years belonging to American Society of Anesthesiologists (ASA), grade I and II, undergoing elective non-ophthalmic surgeries under general anaesthesia. Patients were excluded if they had any acute or chronic ophthalmic disease, had any contraindication to study drug or were taking any medication known to alter IOP. 
The patients were divided into two study groups of 35 patients each using 'slip in the box' method for randomisation. Group 'C' received $10 \mathrm{~mL}$ of normal saline IV (control group) and Group ' $\mathrm{D}$ ' received injection dexmedetomidine as premedication in a dose of $0.5 \mu \mathrm{g} / \mathrm{kg}$ body weight IV with normal saline added to make the total volume of $10 \mathrm{~mL}$.

On arrival in the operation theatre, multi-parameter monitor was connected to the patient and baseline heart rate (HR), non-invasive systolic blood pressure (SBP), diastolic blood pressure (DBP) and mean arterial pressure (MAP), Electrocardiogram (ECG) and oxygen saturation were noted. IOP was measured with Schiotz tonometer after instilling two drops of $4 \%$ lignocaine into each eye by an ophthalmologist who was unaware of the nature of the study. The syringes containing study solutions were prepared by a doctor not involved further in the study. The study solution was administered using an infusion pump over a period of ten minutes prior to induction.

All the patients received standard anaesthesia as follows. Patients received premedication with IV glycopyrrolate 0.2 mg and IV fentanyl $2 \mu \mathrm{g} / \mathrm{kg}$. After pre-oxygenation for three minutes, general anaesthesia was induced with thiopentone sodium in a dose of $5 \mathrm{mg} / \mathrm{kg}$. Succinylcholine was then administered in the dose of $1.5 \mathrm{mg} / \mathrm{kg}$ to achieve muscle relaxation for intubation. After one minute of giving succinylcholine when fasciculations had ceased, the trachea was intubated by a senior anaesthesiologist under direct vision laryngoscopy and position of endotracheal tube was confirmed by auscultation of chest. If intubation could not be performed successfully in the first attempt, the patient was excluded from the study. After securing the airway, anaesthesia was maintained in both the groups with mixture of oxygen, nitrous oxide and isoflurane and injection atracurium.

During intraoperative course HR, MAP and IOP were noted at following time points: Before premedication with study drug (T1), 10 minutes after premedication (T2), 30 seconds after giving thiopentone sodium (T3), 30 seconds after giving succinylcholine (T4), immediately after intubation (T5) and 5 minutes after intubation (T6).

The primary outcome variable of the study was the attenuation of intraocular pressure and the secondary outcome variables were haemodynamic parameters. Any side effects and complications were noted in both the study groups. Hypotension (MAP $<30 \%$ from the baseline) was treated with IV fluids and vasopressors and bradycardia (HR $<50$ beats/min) was treated with atropine. These patients were excluded from the study. Study by convenient allocation technique since the duration of the study was few months. The patients were selected by convenience allocation technique. The sample size estimation was also done at conveniences.

\section{Statistical Analysis}

All observations were tabulated and analysed using independent student ' $\mathrm{t}$ ' test and chi-square test in Statistical Package for Social Sciences (SPSS) software version 22. Statistically, significant difference in findings was considered when p-value was $<0.05$.

\section{RESULTS}

There were no significant differences between the two groups with respect to age, weight, gender distribution and ASA grades. There were also no significant differences between the two groups in terms of baseline HR, MAP and IOP as shown in Table 1.

The values of HR, MAP and IOP at different time intervals in the two study groups are shown in Figures 1, 2 and 3 respectively. Differences in HR between the two groups were not significant at any time. HR increased consistently in Group ' $\mathrm{C}$ ' in response to induction of anaesthesia, succinylcholine administration and endotracheal intubation, whereas in Group 'D,' HR initially decreased after premedication but increased thereafter, though the increments were less compared to Group 'C.' No incidence of bradycardia was reported during the study.

The values of MAP were found to be higher than the baseline after intubation in both the groups. On comparison between the two groups, Group ' $\mathrm{C}$ ' consistently showed higher MAP than Group ' $\mathrm{D}$ ' but this difference was not found to be significant at any point of time. One subject had hypotension in Group 'D' which necessitated intervention, but no such incidences were reported in Group 'C.'

As shown in Figure 2, there was no significant difference in the baseline IOP between both the groups. After premedication IOP decreased in both the groups, but no significant change or difference between the two groups was noted. After giving thiopentone, there was further decrease in IOP but it was significantly lower in Group ' $D$ ' compared to Group ' $C$ ' $(p=0.001)$. Further, after giving succinylcholine and performing intubation, though IOP increased in both the groups but it remained significantly lower in Group ' $D$ ' when compared to Group ' $\mathrm{C}$ ' ( $\mathrm{p}=0.001$ and $<0.001$ respectively). After 5 minutes of endotracheal intubation, IOP returned to its baseline level in both the groups with no significant difference.

Figure 4 shows the incidence of side effects in both the study groups. The only side effect warranting any intervention was single incidence of hypotension in Group 'D.' Rest of the side effects noted were non-serious and infrequent.

\begin{tabular}{|c|c|c|c|}
\hline Characteristic & Group 'D' & Group 'C' & P-value \\
\hline Mean Age (Years) & $\begin{array}{c}39.17 \\
( \pm 11.27)\end{array}$ & $\begin{array}{c}38.57 \\
( \pm 11.52)\end{array}$ & 0.839 \\
\hline $\begin{array}{l}\text { Gender Ratio } \\
\text { (Male: Female) }\end{array}$ & $17: 13$ & $19: 11$ & 0.598 \\
\hline Weight (Kg) & $\begin{array}{c}68.93 \\
( \pm 12.33)\end{array}$ & $\begin{array}{c}68.57 \\
( \pm 12.43)\end{array}$ & 0.909 \\
\hline $\begin{array}{c}\text { ASA Grade } \\
\text { (Grade I: Grade II) }\end{array}$ & $21: 9$ & $22: 8$ & 0.878 \\
\hline Baseline HR (BPM) & $\begin{array}{c}79.60 \\
( \pm 10.83)\end{array}$ & $\begin{array}{c}80.73 \\
( \pm 10.67)\end{array}$ & 0.685 \\
\hline $\begin{array}{l}\text { Baseline MAP } \\
(\mathrm{mmHg})\end{array}$ & $\begin{array}{r}94.40 \\
( \pm 3.99) \\
\end{array}$ & $\begin{array}{r}93.67 \\
( \pm 4.53) \\
\end{array}$ & 0.508 \\
\hline $\begin{array}{l}\text { Baseline IOP } \\
\text { (mmHg) }\end{array}$ & $\begin{array}{c}15.87 \\
( \pm 0.90)\end{array}$ & $\begin{array}{c}15.53 \\
( \pm 1.14)\end{array}$ & 0.213 \\
\hline
\end{tabular}

ASA: American Society of Anesthesiologists. 


\begin{tabular}{|c|c|c|c|}
\hline \multirow[b]{2}{*}{ Time Interval } & \multicolumn{3}{|c|}{ IOP } \\
\hline & $\begin{array}{l}\text { Group } \\
\text { 'D' }\end{array}$ & $\begin{array}{l}\text { Group } \\
\text { 'C' }\end{array}$ & $\begin{array}{c}\text { P- } \\
\text { value }\end{array}$ \\
\hline Baseline $\left(\mathrm{T}_{1}\right)$ & $\begin{array}{c}15.87 \\
( \pm 0.90)\end{array}$ & $\begin{array}{c}15.53 \\
( \pm 1.14)\end{array}$ & 0.213 \\
\hline After premedication $\left(\mathrm{T}_{2}\right)$ & $\begin{array}{c}14.73 \\
( \pm 0.83)\end{array}$ & $\begin{array}{c}14.67 \\
( \pm 0.99)\end{array}$ & 0.779 \\
\hline $\begin{array}{l}\text { After thiopentone sodium } \\
\qquad\left(\mathrm{T}_{3}\right)\end{array}$ & $\begin{array}{c}13.97 \\
( \pm 0.67)\end{array}$ & $\begin{array}{c}14.63 \\
( \pm 0.81) \\
\end{array}$ & $\begin{array}{c}0.001 \\
*\end{array}$ \\
\hline $\begin{array}{l}\text { After succinylcholine } \\
\text { administration }\left(\mathrm{T}_{4}\right)\end{array}$ & $\begin{array}{l}15.93 \\
( \pm 0.83)\end{array}$ & $\begin{array}{l}16.73 \\
( \pm 0.91)\end{array}$ & $\begin{array}{c}0.001 \\
*\end{array}$ \\
\hline $\begin{array}{c}\text { Immediately after } \\
\text { endotracheal intubation }\left(\mathrm{T}_{5}\right)\end{array}$ & $\begin{array}{c}16.10 \\
( \pm 0.76)\end{array}$ & $\begin{array}{c}17.73 \\
( \pm 0.87)\end{array}$ & $\begin{array}{l}<0.00 \\
1^{*}\end{array}$ \\
\hline $\begin{array}{c}5 \text { minutes after endotracheal } \\
\text { intubation }\left(\mathrm{T}_{6}\right)\end{array}$ & $\begin{array}{c}15.91 \\
( \pm 0.93)\end{array}$ & $\begin{array}{c}15.61 \\
( \pm 1.09)\end{array}$ & 0.207 \\
\hline \multicolumn{4}{|c|}{$\begin{array}{c}\text { Table 2. Mean IOP (mmHg) at different Time Intervals in } \\
\text { the Two Study Groups and their Comparison } \\
\text { (Data represented as Mean } \pm \text { SD) }\end{array}$} \\
\hline
\end{tabular}

*Considered significant $(\mathrm{p}<0.05)$

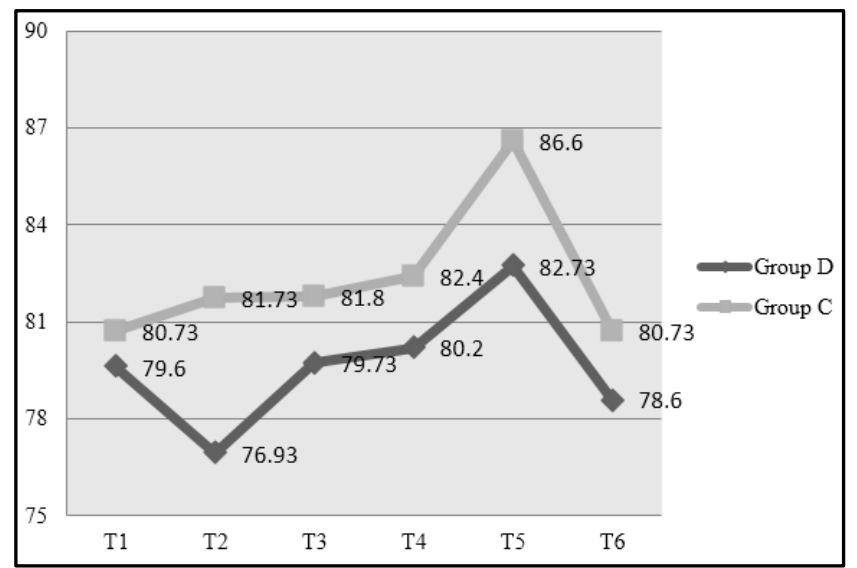

Figure 1. Comparison of Mean HR between the Two Study Groups at different Time Intervals

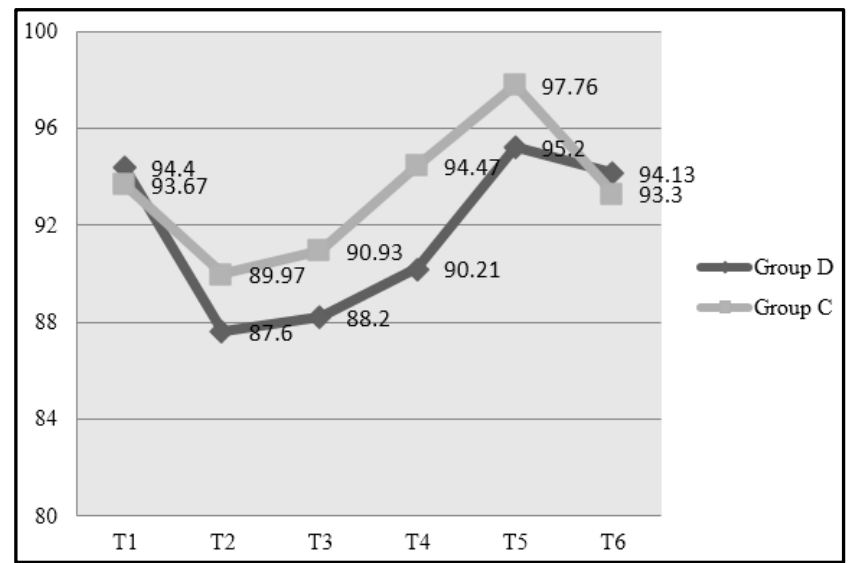

Figure 2. Comparison of Mean MAP between the Two Study Groups at different Time Intervals

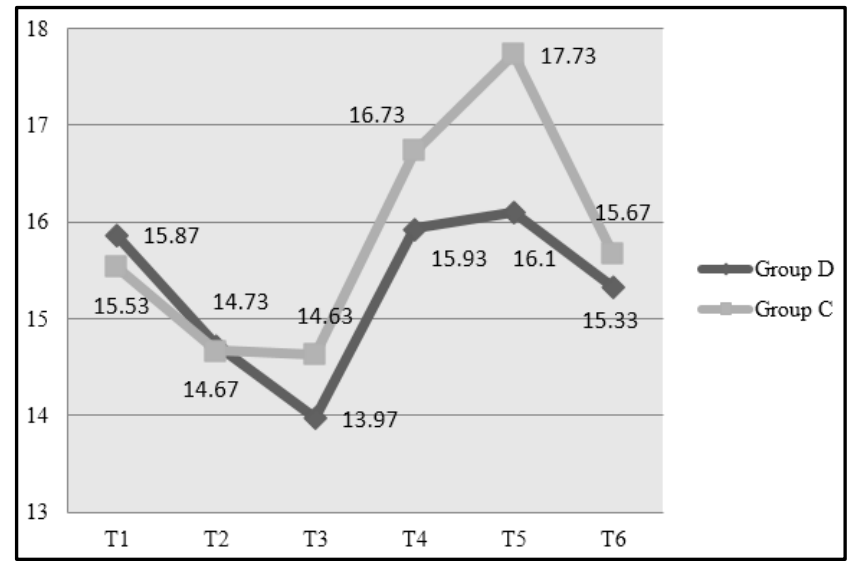

Figure 3. Comparison of Mean IOP between the Two Study Groups at different Time Intervals

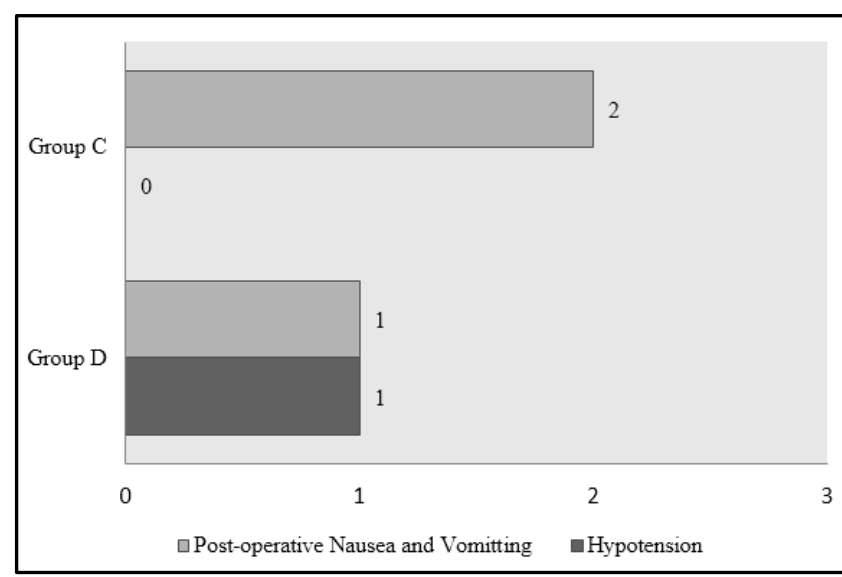

Figure 4. Incidence of Side Effects in the Two Study Groups

\section{DISCUSSION}

Different methods and drugs have been described to blunt the effects of succinylcholine on IOP with variable success. Clonidine has been shown to be effective in preventing the rise in IOP after succinylcholine administration and endotracheal intubation in several studies. $[5,6,7,8]$ Dexmedetomidine, a highly selective alpha-2 adrenergic agonist was approved by the Food and Drug Administration in 1999 for use in humans as a short-term medication $(<24$ hours) for analgesia and sedation in the intensive care unit (ICU). It also has sympatholytic effects with minimal respiratory depression.[9,10] These unique properties make this drug suitable for sedation and analgesia during the perioperative period.[11] Due to these properties, dexmedetomidine premedication prior to administration of local anaesthesia in ophthalmic surgery has been effective in significant reduction of the IOP in many studies, particularly with reference to day-care cataract surgeries.[12,13,14] The main observation from our study was that dexmedetomidine premedication in a dose of $0.5 \mu \mathrm{g} / \mathrm{kg}$ blunted the increase in IOP caused by succinylcholine administration and endotracheal intubation. The administered dexmedetomidine dose of $0.5 \mu \mathrm{g} / \mathrm{kg}$ in the present study was based on experience of a previous study,[15] which used 0.4 and 0.6 $\mu \mathrm{g} / \mathrm{kg}$ dexmedetomidine and showed that increasing the dose of dexmedetomidine to $0.6 \mu \mathrm{g} / \mathrm{kg}$ does not cause any 
significant fall in IOP, while causing increased incidence of cardiovascular depression.

Several studies ${ }^{[15,14,16,17]}$ analysed the blunting of rise in IOP with succinylcholine administration and intubation using dexmedetomidine premedication and revealed observations similar to the results of our study.

The ocular hypotensive effect of dexmedetomidine can be explained by three mechanisms.[17,18] First, it may have a direct vasoconstrictor effect on the afferent blood vessels of the ciliary body leading to reduction of aqueous humour production. Secondly, it may facilitate the drainage of aqueous humour by reducing sympathetically mediated vasomotor tone of the ocular drainage system. Finally, the haemodynamic properties of dexmedetomidine can add to the mechanisms responsible for reduction of IOP.

Dexmedetomidine premedication also blunted the cardiovascular sympathomimetic response to laryngoscopy and intubation in Group 'D' compared to Group 'C,' which was consistent with many previous studies.[11,14] The reason for this can be centrally mediated sympatholytic effects of alpha2 agonists and thereby decreasing norepinephrine release via peripheral presynaptic alpha-2 receptors.

Some authors find the use of succinylcholine in open eye injury to be controversial and an alternative anaesthetic management based on the use of non-depolarising neuromuscular blocking agents, despite their slower onset has been suggested. Despite this debate, most authors still agree on its use in difficult airway cases with salvageable eye situations.[18,19]

The present study had two major limitations. Firstly, it was performed in a small sample size and patients undergoing non-ophthalmic surgeries. There is a need to replicate this study in a larger sample size and in patients undergoing ophthalmic surgeries assessing the actual outcome of such surgeries with dexmedetomidine premedication, as this is the actual group of patients going to benefit the most from the findings of the study. Secondly, as previously stated, haemodynamic action of dexmedetomidine can have a confounding causal relationship with its ocular hypotensive effect and the two effects cannot be isolated from each other. However, in practical sense, this does not limit the use of dexmedetomidine premedication in the setting of emergency ophthalmic surgeries.

\section{Limitation of the Study}

Due to short duration of study, convenience allocation technique was followed. Thus, sampling size was also calculated by convenience. The results of the study cannot be generalised due to the potential bias resulting from the allocation technique and sample size estimation.

\section{CONCLUSION}

The conclusion drawn from this study is that dexmedetomidine premedication in a dose of $0.5 \mu \mathrm{g} / \mathrm{kg}$ significantly blunts the increase in IOP in response to succinylcholine administration and endotracheal intubation compared to control group without causing any additional side-effects and therefore can be used in emergency ophthalmic surgeries for keeping IOP within desirable range.

\section{REFERENCES}

[1] Edmondson L. Intraocular pressure and suxamethonium. Br J Anaesth 1997;79(1):146.

[2] Moeini HA, Soltani HA, Gholami AR, et al. The effect of lidocaine and sufentanil in preventing intraocular pressure increase due to succinylcholine and endotracheal intubation. European Journal of Anaesthesiology 2006;23(9):739-42.

[3] Kaya FN, Yavascaoglu B, Baykara M, et al. Effect of oral gabapentin on the intraocular pressure and haemodynamic responses induced by tracheal intubation. Acta Anaesthesiologica Scandinavica 2008;52(8):1076-80.

[4] Afonso J, Reis F. Dexmedetomidine: current role in anesthesia and intensive care. Rev Bras Anestesiol 2012;62(1):118-33.

[5] Rajan S, Krishnankutty SV, Nair HM. Efficacy of alpha 2 agonists in obtunding rise in intraocular pressure after succinylcholine and that following laryngoscopy and intubation. Anesthesia Essays and Researches 2015;9(2):219-24.

[6] Ghignone M, Noe C, Calvillo O, et al. Anesthesia for ophthalmic surgery in elderly: the effects of clonidine on intraocular pressure, perioperative hemodynamics and anesthetic requirement. Anesthesiology 1988;68(5):707-16.

[7] Polarz H, Bohrer H, Martin E, et al. Oral clonidine premedication prevents the rise in intraocular pressure following succinylcholine administration. Ger J Ophthalmol 1993;2(2):97-9.

[8] Kumar A, Bose S, Bhattacharya A, et al. Oral clonidine premedication for elderly patients undergoing intraocular surgery. Acta Anaesthesiol Scand 1992;36(2):159-64.

[9] Wunsch H, Kahn JM, Kramer AA, et al. Dexmedetomidine in the care of critically ill patients from 2001 to 2007: an observational cohort study. Anesthesiology 2010;113(2):386-94.

[10] Chen BS, Peng H, Wu SN. Dexmedetomidine, an $\propto-2$ adrenergic agonist, inhibits neuronal delayed-rectifier potassium current and sodium current. Br J Anaesth 2009;103(2):244-54.

[11] Gertler R, Brown HC, Mitchell DH, et al. Dexmedetomidine: a novel sedative analgesic agent. Proceedings (Baylor University Medical Center) 2001;14(1):13-21.

[12] Ghodki PS, Sardesai SP, Halikar SS. Dexmedetomidine premedication in cataract surgery under topical anaesthesia: to assess patient and surgeon satisfaction. Southern African Journal of Anaesthesia and Analgesia 2015;21(2):35-9.

[13] Eskandr AM, Abd El-Azeem A, Elmorsy OA. Dexmedetomidine is an effective adjuvant to subtenon block in phacoemulsification cataract surgery. Egyptian Journal of Anaesthesia 2014;30(3):261-6.

[14] Tanuja, Purohit S, Kulshreshtha A. To evaluate the effects of dexmedetomidine on intraocular pressure and haemodynamic changes in response to laryngoscopy and tracheal intubation. J Neuroanaesthesiol Crit Care 2014;1(3):178-82. 
[15] Pal CK, Ray M, Sen A, et al. Changes in intraocular pressure following administration of suxamethonium and endotracheal intubation: influence of dexmedetomidine premedication. Indian J Anaesth 2011;55(6):573-7.

[16] Mowafi HA, Aldossary N, Ismail SA, et al. Effect of dexmedetomidine premedication on the intraocular pressure changes after succinylcholine and intubation. Br J Anaesth 2008;100(4):485-9.
[17] Banga PK, Singh DK, Dadu S, et al. A comparative evaluation of the effect of intravenous dexmedetomidine and clonidine on intraocular pressure after Suxamethonium and intubation. Saudi Journal of Anaesthesia 2015;9(2):179-83.

[18] Murgatroyd H, Bembridge J. Intraocular pressure. Contin Educ Anaesth Crit Care and Pain 2008;3:100-3.

[19] Chidiac EJ, Raiskin AO. Succinylcholine and the open eye. Ophthalmol Clin North Am 2006;19(2):279-85. 